\title{
Obesity Status among Breast Cancer Patients Based on the Korean Obesity Index Standard Reference in the Aging Community
}

\author{
Jung Sun Lee, M.D., Ph.D. \\ Department of Surgery, Haeundae Paik Hospital, College of Medicine, Inje University, Busan, Korea
}

Purpose: Obesity and age are known risk factors for breast cancer. However, as these factors tend to be reported together, their individual contributions are unclear; age might confound the impact of obesity on outcomes. This study investigated the status of obesity in patients with breast cancer and its correlation with either clinical characteristics or overall survival, using the Korean obesity index standard reference (KOISR) which stratified by age, and matched with outcomes of the local general population. Methods: We conducted a single-center retrospective study between January 2014 and December 2018. A total of 429 patients diagnosed with and treated for breast cancer were categorized according to the World Health Organization (WHO) body mass index (BMI) classification for Asian populations or KOISR. We examined the impact of the KOISR on the current status of obesity, and survival outcomes with the log-rank test. Results: In a sample of 418 patients, the distribution of obese, normal, and low BMI was $143(34.2 \%), 266(63.6 \%)$, and $9(2.2 \%)$ patients, respectively. When categorized by the KOISR, $52.6 \%$ of all patients placed above the 75th percentile; advanced breast cancer diagnosis was likely in this group ( $p=0.030)$. BMl correlated with age (19.4\% of women with less than 50 years and $45.4 \%$ of women aged 50 years and above were obese; $p=0.001$ ). No significant difference in overall survival $(p=0.340)$ was observed between KOISR score-based groups $(<75$ th percentile vs. $\geq 75$ th percentile), stratified by stage. Conclusion: Adjusted with a community and age (KOISR), patients with breast cancer have a relatively higher BMI than the general population in a similar community and generation. Women with a high KOISR score were also more likely to have advanced breast cancer than non-obese women. Nevertheless, high BMI was not a major factor affecting survival in this study.

Key Words: Age, Breast neoplasms, Body mass index, Obesity, Survival

\section{INTRODUCTION}

According to the third national health and nutrition survey of Korea, which was reported in 2001 and included a total of 6,569 Korean adults $[1,2]$, the nation's overall prevalence of obesity (defined as body mass index $\left.[\mathrm{BMI}] \geq 25 \mathrm{~kg} / \mathrm{m}^{2}\right)$ was $30.6 \%(32.4 \%$ and 29.4\% in men and women, respectively). Previously, Song et al. [3] reported a dramatic increase in obesity rates $\left(B M I \geq 30 \mathrm{~kg} / \mathrm{m}^{2}\right)$ in South Korea over a period of 11 years. Concurrently, the incidence and risk of obesity-related disease increased.

In general, obesity is regarded as a risk and poor prognostic factor in some types of breast cancer. Obese patients tend to have larger tumors and more positive nodes [4]. Several reports have suggested that obesity leads to poor prognosis by increasing circulating plasma levels of estrogen, insulin, and insulin-like growth factor that promote tumor

Correspondence: Jung Sun Lee, M.D., Ph.D.

Department of Surgery, Haeundae Paik Hospital, College of Medicine, Inje University, 875 Haeun-daero, Haeundae-gu, Busan 48108, Korea Tel: +82-51-797-2437, Fax: +82-51-797-1010, E-mail: gsjslee@gmail.com Received: Apr 3, 2020 Revised: Jun 27, 2020 Accepted: Aug 30, 2020 growth $[5,6]$. Recent meta-analyses have examined the relationship between BMI and survival in a large number of patients $[7,8]$. Chan $[8]$ analyzed data from 213,075 patients across 82 studies, summarizing relative risk of overall and breast cancer-specific mortality in obese vs. normal-weight patients at baseline as 1.41 (95\% confidence interval [CI], 1.29-1.53) and 1.35 (95\% CI, 1.24-1.47), respectively.

Compared to Western populations, in Korea, the prevalence of breast cancer in patients younger than 50 years is higher; these women tend to have relatively lower BMI than women aged 50 years and above $[9,10]$. These population differences might be indicative of the role of obesity in breast cancer. However, the impact of obesity might be mediated by patient age in addition to ethnicity. For example, Asian populations tend to have a proportionally higher total body and abdomen fat percentage than Caucasians; as a result, these populations tend to develop obesity-related complications at relatively lower BMI [11]. The Korean Health Insurance Service (NHIS) developed the Korean obesity index standard reference (KOISR) in 2016 as a tool for individual obesity assessment in the Korean context [12]. Actually, the KOISR is a representative tool; for example, in Korea, women in their twenties 
have relatively normal BMI, women above the 75th percentile were considered as having normal BMI, but women in their mid-forties above the 75th percentile had BMI $\geq 25 \mathrm{~kg} / \mathrm{m}^{2}$ [13].

However, previous studies [14,15] in Korea have used as reference different definitions of obesity (BMI $\geq 30 \mathrm{~kg} / \mathrm{m}^{2}$ ) rather than the WHO's criteria for Asian populations. As a result, the effects of obesity on survival may have been overestimated or underestimated. In this study, we investigated the relationship between BMI and clinical characteristics or overall survival (OS), using KOISR in a community-dwelling population.

\section{METHODS}

\section{Study population}

A single-center retrospective observational study was performed (Haeundae-paik Hospital, Busan, Korea) between January 2014 and July 2018. A total of 429 patients were diagnosed with and treated for breast cancer during this period. Male and non-Korean patients were excluded from this study, as were patients with other tumors (sarcoma, phyllodes tumor, and lymphoma). Data from a total of 418 patients were included in the final analysis; patients were categorized into three weight groups based on their BMI, according to the modified WHO obesity criteria for Asian populations (low weight: BMI $<18 \mathrm{~kg} / \mathrm{m}^{2}$, normal weight: BMI $18 \leq-<25 \mathrm{~kg} / \mathrm{m}^{2}$, obesity: BMI $\geq 25$ $\mathrm{kg} / \mathrm{m}^{2}$ ) [16]. BMI was calculated by dividing weight in kilograms by the square of height in meters. BMI was measured at the time of diagnosis. The study was approved by the Institutional Review Board of the Inje University Haeundae-paik Hospital (IRB No. 2020-02-034).

\section{The Korean obesity index standard reference}

The NHIS has worked with the National Institute of Technology and the Korean Institute of Standards and Sciences to develop the KOISR, which reflects unique characteristics of Koreans; it was registered as a national reference standard on December 16, 2016. NHIS used data from 16.4 million health check records $(2013,2014)$, acquired during nation-wide health checks. In particular, the existing health screening data was applied to the concept of uncertainty reflecting the error range; the uncertainty and the error range of the equipment due to repetitive measurement was not covered by the more sophisticated data. The new reference was stratified by BMI, sex, age, and Korean province, and released to the public [12]. We converted all BMI data to the KOISR, and defined "high" KOISR as values within the 75th percentile or above, compared to age- and gender-matched controls sampled from the same community (Supplementary Table 1,2).

\section{Statistical analysis}

Descriptive statistics were summarized as absolute and relative frequencies. Continuous and categorical variables were compared among BMI groups using one-way analysis of variance and the $\chi^{2}$ test, respectively. Survival outcomes were analyzed in terms of overall survival (OS) and disease-free survival (DFS). OS was defined as the time from the first diagnosis of primary breast cancer to death from any cause and DFS was defined as time from diagnosis of breast cancer to death due to breast cancer or following a breast cancer-related event. Survival rate of patients lost to follow-up was calculated using the date of last follow-up. Survival curves for all three BMI groups were estimated using the Kaplan-Meier method, and the log-rank test was used to evaluate statistical significance of between-group differences in survival. All reported $p$-values were two-sided, with the level of significance established at $p<0.050$. All statistical analyses were performed using SAS software, version 9.4 (SAS Institute Inc., Cary, USA).

Table 1. Correlation between body mass index and clinical characteristics $(n=418)$

\begin{tabular}{|c|c|c|c|c|c|}
\hline \multirow{2}{*}{ Characteristic } & & \multicolumn{3}{|c|}{ BMI } & \multirow[b]{2}{*}{$p$-value } \\
\hline & & $\begin{array}{l}\text { Normal } \\
\text { No. (\%) }\end{array}$ & $\begin{array}{l}\text { Obesity } \\
\text { No. (\%) }\end{array}$ & $\begin{array}{l}\text { Low } \\
\text { No. (\%) }\end{array}$ & \\
\hline \multirow[t]{2}{*}{ Age (yr) } & $<50$ & $140(52.6)$ & $35(24.4)$ & $5(55.5)$ & 0.001 \\
\hline & $\geq 50$ & $126(47.4)$ & $108(75.6)$ & $4(44.4)$ & \\
\hline \multirow[t]{2}{*}{ Menopause } & Pre- & $174(75.3)$ & $52(22.5)$ & $5(2.2)$ & 0.001 \\
\hline & Post- & $91(48.9)$ & $91(48.9)$ & $4(2.2)$ & \\
\hline \multirow[t]{5}{*}{ Stage } & 0 & $55(20.7)$ & $26(18.2)$ & $2(22.2)$ & 0.090 \\
\hline & I & $115(43.2)$ & $52(36.4)$ & $4(44.4)$ & \\
\hline & $\|$ & $73(27.4)$ & $47(32.8)$ & $2(22.2)$ & \\
\hline & III & $21(7.8)$ & $14(9.8)$ & $1(11.1)$ & \\
\hline & IV & $2(0.7)$ & $4(2.7)$ & 0 & \\
\hline \multirow[t]{2}{*}{ HER2 } & Negative & $207(77.8)$ & $113(79.0)$ & $8(88.8)$ & 0.520 \\
\hline & Positive & $51(19.2)$ & $21(14.7)$ & 1 (11.1) & \\
\hline \multirow[t]{2}{*}{ ER } & Negative & $97(36.5)$ & 38 (26.6) & $1(11.1)$ & 0.080 \\
\hline & Positive & $168(63.1)$ & $103(72.0)$ & $8(88.8)$ & \\
\hline \multirow[t]{2}{*}{ PR } & Negative & $123(46.2)$ & $59(41.2)$ & $4(44.4)$ & 0.700 \\
\hline & Positive & $137(51.5)$ & $78(54.5)$ & $5(55.5)$ & \\
\hline \multirow[t]{2}{*}{ Ki-67 } & $\geq 14 \%$ & $120(45.1)$ & $66(46.2)$ & $3(33.3)$ & 0.360 \\
\hline & $<14 \%$ & $136(51.1)$ & $67(46.8)$ & $5(55.5)$ & \\
\hline
\end{tabular}

$\mathrm{BMI}=$ body mass index; HER2 = human epidermal growth factor receptor 2; $\mathrm{ER}=$ estrogen receptor; $\mathrm{PR}=$ progesterone receptor. 


\section{RESULTS}

\section{Patients' clinical characteristics and obesity}

The distribution of BMI at diagnosis included 266 (63.6\%), 143 (34.2\%), and 9 patients (2.2\%) with normal BMI, obesity, and low BMI,

Table 2. Correlation between Korean obesity index standard reference and clinical characteristics

\begin{tabular}{|c|c|c|c|c|}
\hline \multicolumn{2}{|l|}{ Characteristic } & \multicolumn{3}{|c|}{$<75$ percentile $\geq 75$ percentile $p$-value } \\
\hline \multicolumn{2}{|c|}{ Tumor size $(\mathrm{cm})^{*}$} & $1.91 \pm 1.3$ & $2.15 \pm 1.87$ & 0.026 \\
\hline \multicolumn{2}{|c|}{ Positive lymph node (No.)* } & $1.02 \pm 4.2$ & $1.75 \pm 5.0$ & 0.011 \\
\hline \multicolumn{2}{|l|}{ Characteristic } & $\begin{array}{l}\text { No. }(\%) \\
(n=198)\end{array}$ & $\begin{array}{l}\text { No. }(\%) \\
(n=220)\end{array}$ & $p$-value \\
\hline \multirow[t]{2}{*}{ Menopause } & Pre- & $132(66.7)$ & $99(45.0)$ & $<0.001$ \\
\hline & Post- & $66(33.3)$ & $121(55.0)$ & \\
\hline \multirow[t]{5}{*}{ Stage } & 0 & $42(21.2)$ & $41(18.6)$ & 0.030 \\
\hline & 1 & $88(44.4)$ & $83(37.7)$ & \\
\hline & $\|$ & $54(27.3)$ & $68(30.9)$ & \\
\hline & III & $13(6.6)$ & $23(10.5)$ & \\
\hline & IV & $1(0.5)$ & $5(2.3)$ & \\
\hline \multirow[t]{2}{*}{ HER2 } & Negative & $151(76.3)$ & $171(77.7)$ & 0.720 \\
\hline & Positive & $47(23.7)$ & $49(22.3)$ & \\
\hline \multirow[t]{2}{*}{ ER } & Negative & $66(33.3)$ & $70(31.8)$ & 0.840 \\
\hline & Positive & $131(66.2)$ & $148(67.3)$ & \\
\hline \multirow[t]{2}{*}{ PR } & Negative & $87(43.9)$ & $99(45.0)$ & 0.560 \\
\hline & Positive & $107(54.0)$ & $113(51.4)$ & \\
\hline \multirow[t]{2}{*}{ Ki-67 } & $\geq 14 \%$ & $92(46.5)$ & 97 (44.1) & 0.650 \\
\hline & $<14 \%$ & $98(49.5)$ & $110(50.0)$ & \\
\hline
\end{tabular}

$\mathrm{HER} 2$ = human epidermal growth factor receptor 2; $E R=$ estrogen receptor; $\mathrm{PR}=$ progesterone receptor.

${ }^{*}$ Mean \pm SD.

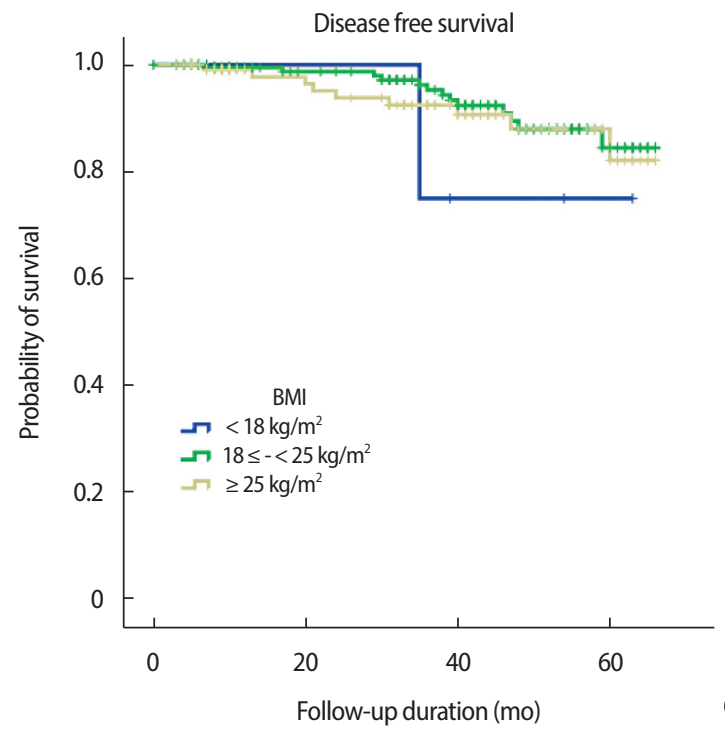

respectively. Concurrently, 52.6\% (220/418) of patients had high $\mathrm{KO}$ ISR scores, suggesting breast cancer patients in the studied community had higher BMI than women in the general population. BMI cor related with age; 19.4\% (35/180) of patients with obesity were younger than 50 years and $45.4 \%(108 / 238)$ of patients with obesity were aged 50 years and above $(p<0.001)$ (Table 1$)$. There was no correlation between BMI at diagnosis and disease stage $(p=0.090)$ (Table 1); however, there was a correlation between KOISR percentile and disease stage

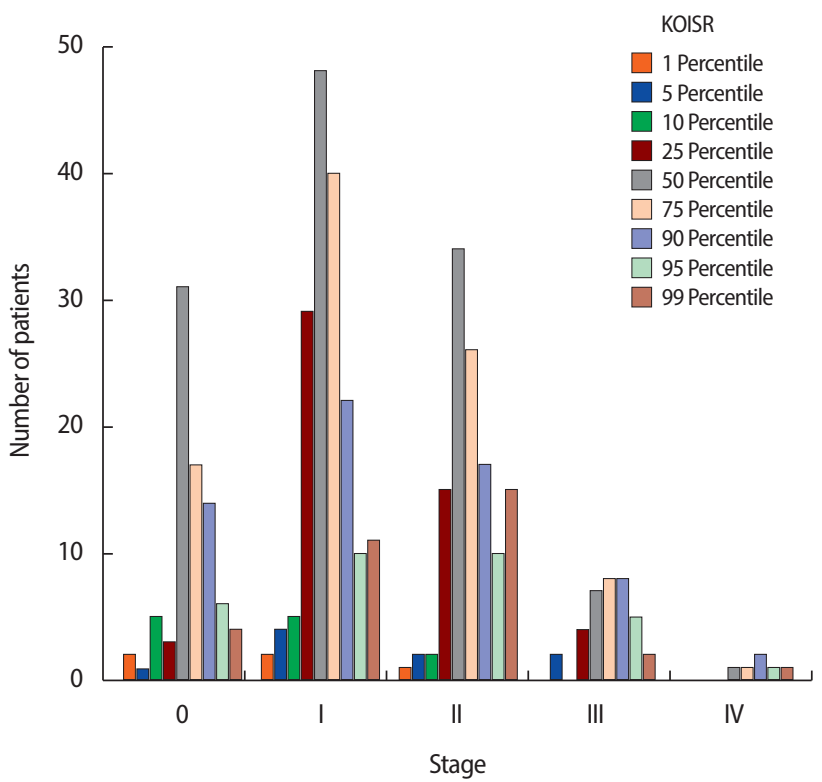

Figure 1. Distribution of the Korean obesity index standard reference (KOISR) in 418 patients with breast cancer according to stage.

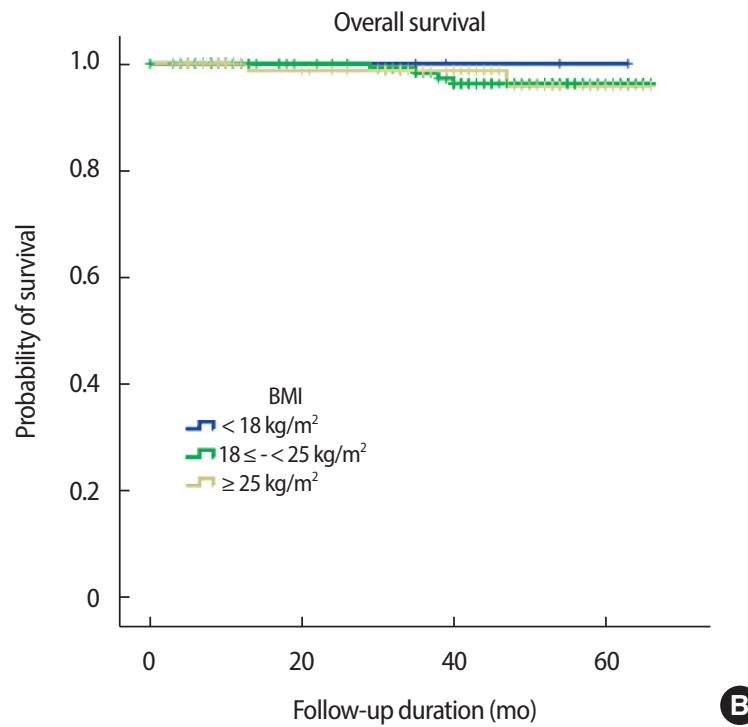

Figure 2. Disease-free survival (DFS) (A) and overall survival (OS) (B) according to body mass index (BMI) (OS, log-rank test, $p=0.980$; DFS, log-rank test, $p=0.900$ ). 
$(p=0.030)$ (Table 2). In addition, postmenopausal women had a positive correlation with obesity (Table 1,2). Specifically, advanced stage disease (stage III/IV) was more likely in women with high KOISR scores (Figure 1). Correlations between other clinical factors and BMI or the KOISR are shown in Table 1 and 2.

Clinical outcomes and obesity defined by BMI or the KOISR

The mean duration of follow up was 33.3 months, during which

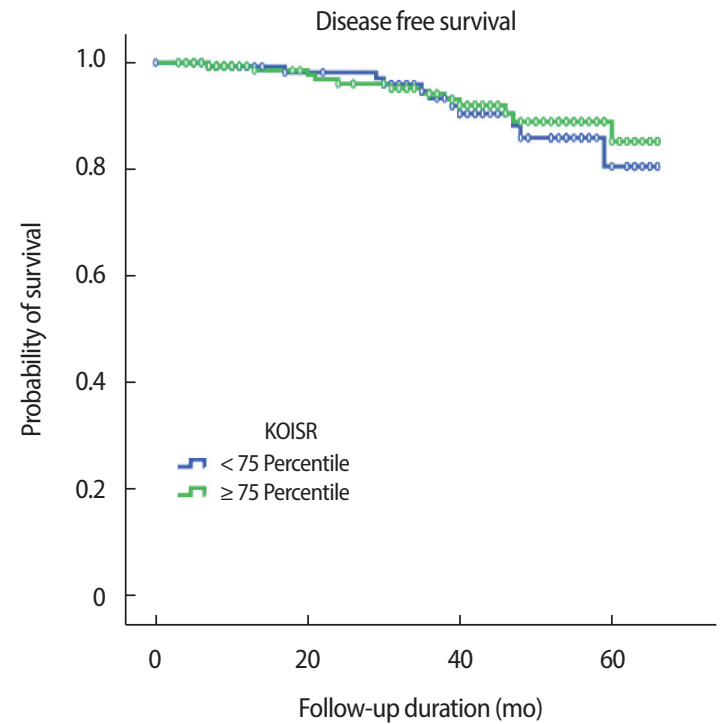

24 events occurred (17 recurrences, 6 deaths, 1 alive with disease). After excluding patients with in situ cancer (113 patients), data from 305 patients with invasive breast cancer were analyzed ( 24 events). There was no relationship between either OS or DFS and BMI at diagnosis (OS, $p=0.980$; DFS, $p=0.900$ ) (Figure 2). This finding was consistent with that achieved using the KOISR (OS, $p=0.340$; DFS, $p=0.940$ ) (Figure 3). When analyzed by menopausal status, DFS did not show any correlation with either status of BMI $(p=0.630)$ (Figure 4 ) or KO$\operatorname{ISR}(p=0.240)($ Figure 5$)$.

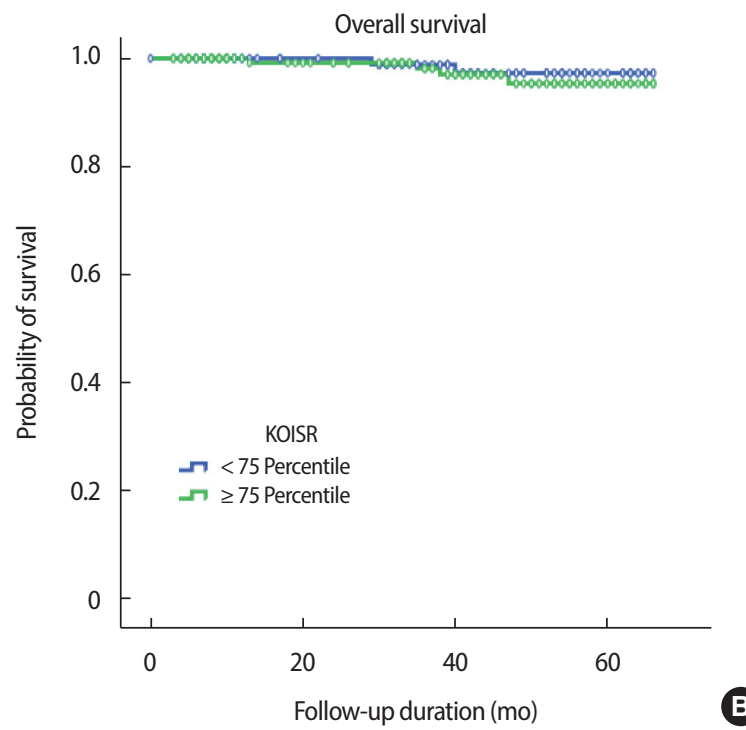

Figure 3. Disease-free survival (DFS) (A) and overall survival (OS) (B) according to the Korean obesity index standard reference (KOISR) score (OS, log-rank test, $p=0.340 ; \mathrm{DFS}$, log-rank test, $p=0.940$ ).
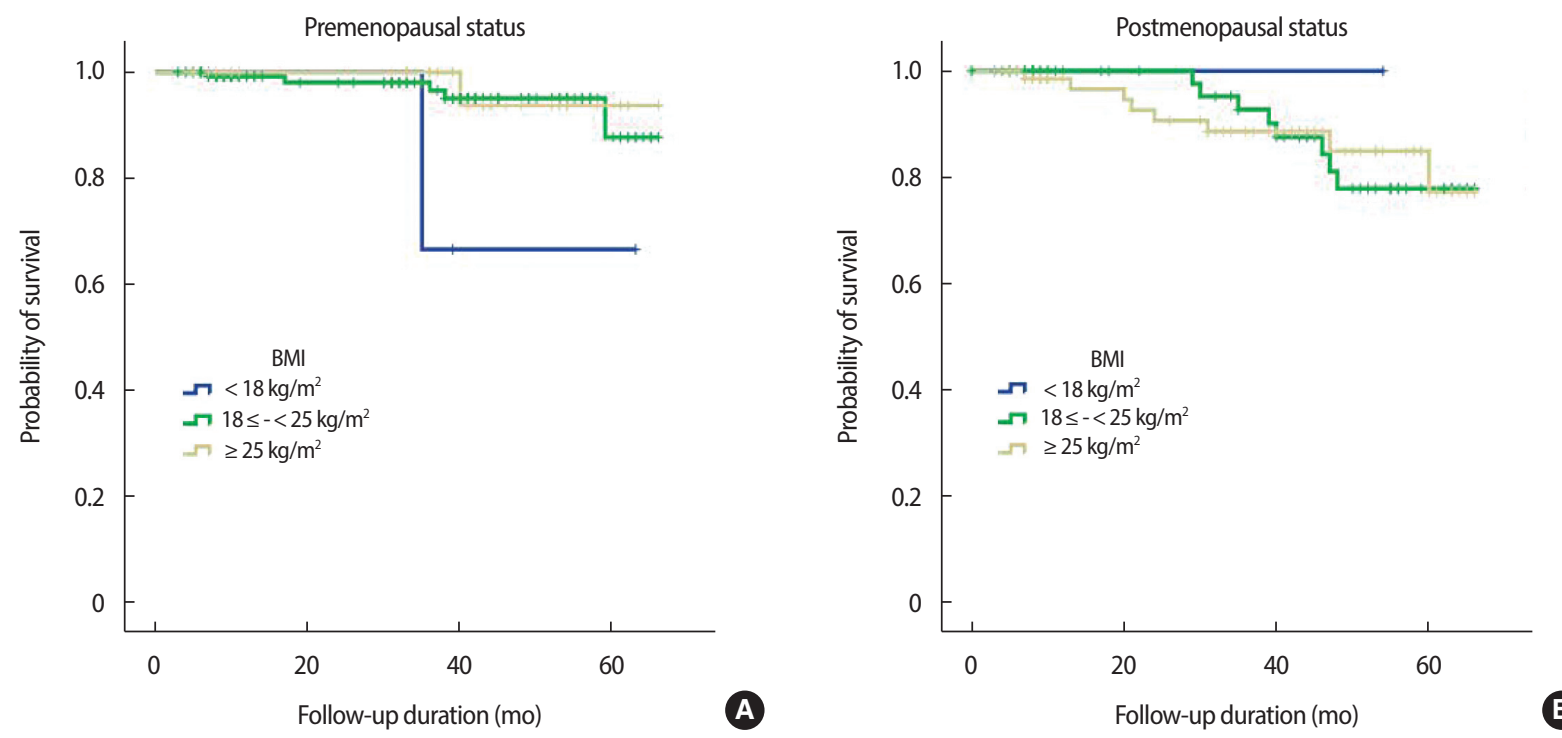

Figure 4. Disease-free survival (DFS) in premenopausal women (A) and postmenopausal women (B) according to BMI (DFS, log-rank test, $p=0.630$ ). 

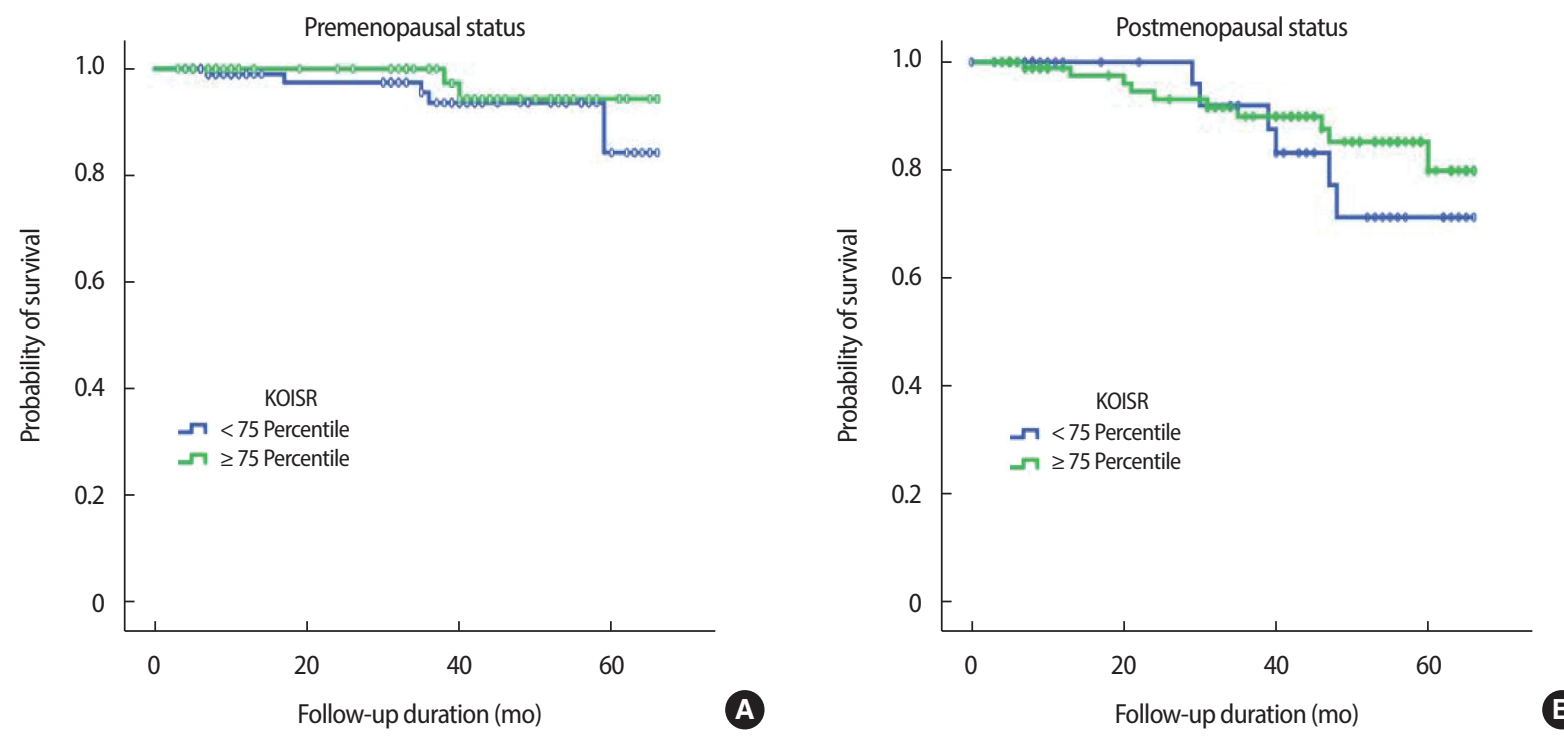

Figure 5. Disease-free survival (DFS) in premenopausal women (A) and postmenopausal women (B) according to the Korean obesity index standard reference (KOISR) score (DFS, log-rank test, $p=0.240$ ).

\section{DISCUSSION}

This is the first Korean community-based study of the relationship between obesity and survival among breast cancer patients, using data from medical records. Previous retrospective studies on Korean breast cancer patients were large, multi-center, nationwide studies that included relatively younger breast cancer patients [14,15]. Both Busan and Kyung-Nam province have aging populations; the median age of breast cancer patients therein was higher than the median age of breast cancer patients across Korea [17]. Since 2010, the chronological peak incidence has moved to later in life, with the present median age of onset estimated at 50 years [10]. Although the association between high BMI and breast cancer risk is well established, it is based on evidence from studies conducted in Western countries. In East Asia, Chow et al. [18] found that BMI at diagnosis was positively correlated with the risk of breast cancer among postmenopausal, but not premenopausal, women. Kang et al. [19] showed that an increase in BMI positively correlated with breast cancer incidence through a single-center's screening data (odds ratio $\mathrm{n}=2.09, p=0.012$ ) in Korea. In Japan, a nationwide prospective sister cohort study suggested that postmenopausal women who are metabolically unhealthy (defined based on characteristics such as elevated blood pressure, antidiabetic drug use, or cholesterol-lowering medication use) may be at increased risk of breast cancer despite normal BMI. Additionally, an inverse as- sociation between premenopausal breast cancer risk and the metabolically healthy overweight/obese phenotype (hazard ratio, $0.71 ; 95 \%$ CI, 0.52-0.97) has been reported [20].

The presence of a positive association between advanced disease stage at diagnosis and obesity has been corroborated by several studies [21,22]. Deglise et al. [22] reported on a population-based study, showing that obesity $\left(\mathrm{BMI}>30 \mathrm{~kg} / \mathrm{m}^{2}\right)$ affects presentation and diagnostic assessment of women with breast cancer. Obese women were nearly twice as likely as their normal-/under-weight counterparts to present with advanced stage (stage III/IV) disease at diagnosis. Cui et al. [23] hypothesized that increased breast size in obese women may delay discovery of a breast tumor. As a result, the relationship between obesity and breast cancer stage at diagnosis was stronger among women younger than 50 years than among women aged 50 years or older. Also, this finding may be of considerable concern, given the increasing prevalence of obesity in the United States and the prognosis associated with late-stage tumors, but in Korea, where additional ultrasonography has been a popular screening method, this hypothesis needs to be studied for women with small- or medium-sized breasts. High BMI increased the risk of breast cancer in postmenopausal women in Western countries and in Westernized Asia. It is plausible that various biological factors related to obesity might stimulate tumor progression. For example, a high concentration of bioavailable estrogen due to aromatization of circulating androgens to estrogen in adipose tis- 
sues may have a mitogenic effect on breast cancer cells. However, the hypothesis that high BMI is associated with lower levels of aromatase inhibitors due to increased amount of adipose tissue and aromatase activity was not supported in multivariate analysis [24].

Previous studies on the association between BMI and breast cancer prognosis in Asian women showed that high BMI $[15,25]\left(\geq 25 \mathrm{~kg} / \mathrm{m}^{2}\right)$ had an adverse effect on OS but not on DFS. Furthermore, stratified by age, BMI was significantly and negatively associated with OS in patients aged 50 years and above; however, this effect was not detected in younger Chinese women. Duration of follow-up could account for this discrepancy. The TEAM (tamoxifen exemestane adjuvant multinational) trial showed an adverse association between short-term $(2.75$ years) cancer prognosis and obesity in patients on adjuvant tamoxifen; however, this association did not hold over a long term (5.1 years) [26].

Several previous studies have shown a relationship between obesity and either OS or DFS. Kamineni et al. [27] reported that, compared to normal-weight women, obese women are at increased risk of disease recurrence and disease-specific mortality within 10 years of diagnosis with rates estimated at $12.2 \%$ and $6.9 \%$, respectively. Although there is no association between BMI and all-cause mortality, obese women have been shown to have significantly faster-growing tumors. This study involved a cohort of 3,385 women enrolled in the national surgical adjuvant breast and bowel project protocol B-14, which showed no association between obesity and increased risk of recurrence in lymph node-negative, estrogen receptor-positive breast cancer; however, the same study revealed an association between obesity and increased risk of contralateral breast cancer and all-cause premature mortality [28].

Considering breast cancer stage, moderate to severe obesity is associated with poor prognosis in invasive breast cancer; this association was also detected in women with stage I disease, and was independent of age and treatment [29]. Gennari et al. [30] showed that higher BMI did not influence prognosis in high-risk early breast cancer patients treated with chemotherapy. These authors suggest that in an aggressive biological subtype of breast cancer, the impact of host factors on patient prognosis could be minor.

In conclusion, women with high BMI (KOISR $\geq 75$ th percentile) has a positive association with risk of breast cancer in all ages, as well as a positive correlation with advanced breast cancers. Although the clinical usefulness of the KOISR needs to be studied further, it may be a more representative reference to explain the status of individual obesity in patients with breast cancer. Despite a short follow-up period, obesity did not have an adverse effect on OS; however, whether this effect differed between disease stage (early vs. advanced) remains unclear. Additionally, relevant evidence should be incorporated into comorbidity assessment.

\section{CONFLICT OF INTEREST}

The author declares that she has no competing interests.

\section{REFERENCES}

1. Kim DM, Ahn CW, Nam SY. Prevalence of obesity in Korea. Obes Rev 2005;6:117-21.

2. Korean Ministry of Health and Welfare. Report on national health and nutrition survey 2001. Seoul: Korean Ministry of Health and Welfare; 2002.

3. Song HJ, Hwang J, Pi S, Ahn S, Heo Y, Park S, et al. The impact of obesity and overweight on medical expenditures and disease incidence in Korea from 2002 to 2013. PLoS One 2018;13:e0197057.

4. Kim YA, Lee CW. Effects of obesity on breast cancer stage at diagnosis in Korean women. Eur J Cancer Prev 2004;13:13-7.

5. Picon-Ruiz M, Pan C, Drews-Elger K, Jang K, Besser AH, Zhao D, et al. Interactions between adipocytes and breast cancer cells stimulate cytokine production and drive Src/Sox/miR-302b- medicated malignant progression. Cancer Res 2016;76:491-504.

6. Simone V, D’Avenia M, Argentiero A, Felici C, Rizzo FM, De Pergola $\mathrm{G}$, et al. Obesity and breast cancer: molecular interconnection and potential clinical applications. Oncologist 2016;21:404-17.

7. Niraula S, Ocana A, Ennis M, Goodwin PJ. Body size and breast cancer prognosis in relation to hormone receptor and menopausal status: a meta-analysis. Breast Cancer Res Treat 2012;134:769-81.

8. Chan DS, Vieira AR, Aune D, Bandera EV, Greenwood DC, McTiernan A, et al. Body mass index and survival in women with breast cancer: systemic literature review and meta-analysis of $82 \mathrm{fol}-$ low-up studies. Ann Oncol 2014;25:1901-14.

9. Yoo KY, Kang D, Park SK, Kim SU, Shin A, Yoon H, et al. Epidemiology of breast cancer in Korea: occurrence, high-risk groups, and prevention. J Korean Med Sci 2002;17:1-6. 
10. Korean Breast Cancer Society. Breast cancer facts \& figures 2018. Seoul: Korean Breast Cancer Society; 2018.

11. Korean Ministry of Health and Welfare. Report on national health and nutrition survey 1995. Seoul: Korean Ministry of Health and Welfare; 1996.

12. Korean obesity index standard reference-v.1.2017. National Health Insurance Sharing Service. https://nhiss.nhis.or.kr/bd/ab/bdabf004cv.do. Accessed March 21th,2020.

13. Kim YY, Seo E, Baek J, Ha S, Kang H. Effects of the relative distribution of body mass index on the incidence of hypertension and diabetes mellitus, using the Korean obesity index. Metab Syndr Relat Disord 2019;17:108-14.

14. Lee KH, Kean B, Im SA, Kim TY, Han SW, Oh DY, et al. Body mass index is not associated with treatment outcomes of breast cancer patients receiving neoadjuvant chemotherapy: Korean data. J Breast Cancer 2012;15:427-33.

15. Chung IY, Lee JW, Lee JS, Park YR, Min YH, Lee U, et al. Interaction between body mass index and hormone receptor status as a prognostic factor in lymph node -positive breast cancer. PLoS One 2017; 12:e0170311.

16. WHO expert consultation. Appropriate body-mass index for Asian populations and its implications for policy and intervention strategies. Lancet 2004;363:157-63.

17. Annual report of cancer statistics in Korea in 2016. Ministry of Health and Walfare. http://ncc.re.kr/ cancerStatsList.ncc?sea. Accessed Feb 14th,2020.

18. Chow LWC, Lui KL, Chan J, Chan TC, Ho PK, Lee WY, et al. Association between body mass index and risk of formation of breast cancer in Chinese women. Asian J Surg 2005;28:179-84.

19. Kang HS, Kim J, Kim J, Lee HB, Shin HC, Han WS, et al. Analysis of the relationship between body mass index and breast cancer incidence in Korean women. J Breast Dis 2016;4:64-9.

20. Park YM, White AJ, Nichols HB, O’Brien KM, Weinberg CR, Sandler DP. The association between metabolic health, obesity phenotype and the risk of breast cancer. Int J Cancer 2017;140:2657-66.
21. Kim YA, Lee CW. Effects of obesity on breast cancer stage at diagnosis in Korean women. Eur J Cancer Prev 2004;13:13-7.

22. Deglise C, Bourchardy C, Burri M, Usel M, Neyroud-Caspar I, Vlastos $G$, et al. Impact of obesity on diagnosis and treatment of breast cancer. Breast Cancer Res Treat 2010;120:185-93.

23. Cui Y, Whiteman MK, Flaws JA, Langenberg P, Tkaczuk KH, Bush TL. Body mass and stage of breast cancer at diagnosis. Int J Cancer 2002;98:279-83.

24. Goodwin PJ. Obesity and endocrine therapy: host factors and breast cancer outcome. Breast 2013;22:S44-7.

25. Wang X, Hui TL, Wang MQ, Liu H, Li RY, Song ZC. Body mass index at diagnosis as a prognostic factor for early- stage invasive breast cancer after surgical resection. Oncol Res Treat 2019;42:190-6.

26. Seynaeve C, Hille E, Hasenburg A, Rea D, Markopoulos C, Hozumi $\mathrm{Y}$, et al. The impact of body mass index on the efficacy of adjuvant endocrine therapy in postmenopausal hormone sensitive breast cancer patients: exploratory analysis from the TEAM study. Cancer Res 2010;70:Abstract S2-3.

27. Kamineni A, Anderson ML, White E, Taplin SH, Porter P, BallardBarbash R, et al. Body mass index, tumor characteristics, and prognosis following diagnosis of early-stage breast cancer in a mammographically screened population. Cancer Causes Control 2013; 24:305-12.

28. Dignam JJ, Wieand K, Johnson KA, Fisher B, Xu L, Mamounas EP. Obesity, tamoxifen use, and outcomes in women with estrogen receptor-positive early-stage breast cancer. J Natl Cancer Inst 2003;95: 1467-76.

29. Robinson PJ, Bell RJ, Davis SR. Obesity is associated with a poorer prognosis in women with hormone receptor positive breast cancer. Maturitas 2014;79:279-86

30. Gennari A, Amadori D, Scarpi E, Farolfi A, Paradiso A, Mangia A, et al. Impact of body mass index (BMI) on the prognosis of high-risk early breast cancer (EBC) patients treated with adjuvant chemotherapy. Breast Cancer Res Treat 2016;159:79-86. 
Jung Sun Lee. Obesity and Breast Cancer

Supplementary Table 1. Korean obesity index standard reference in Busan

\begin{tabular}{|c|c|c|c|c|c|c|c|c|c|c|c|c|c|c|c|}
\hline \multirow{2}{*}{ Sex } & \multirow{2}{*}{$\begin{array}{l}\text { Age } \\
(y r)\end{array}$} & \multirow{2}{*}{$\begin{array}{c}\text { Sample } \\
\text { size (No.) }\end{array}$} & \multirow{2}{*}{$\begin{array}{l}\text { Mean } \\
\text { (mean) }\end{array}$} & \multirow{2}{*}{$\begin{array}{c}\text { Uncertainty } \\
\left(\mathrm{kg} / \mathrm{m}^{2}\right)\end{array}$} & \multicolumn{2}{|c|}{$\mathrm{Cl}(95 \%)$} & \multicolumn{9}{|c|}{ Percentile } \\
\hline & & & & & Lower & Upper & 1th & 5th & 10th & 25th & 50th & 75th & 90th & 95th & 99th \\
\hline \multirow[t]{27}{*}{ Female } & $20-24$ & 15,393 & 21.40 & 0.84 & 17.26 & 28.07 & 16.1 & 17.3 & 17.9 & 19.1 & 20.7 & 22.8 & 25.7 & 28.1 & 33.9 \\
\hline & $25-26$ & 13,677 & 21.23 & 0.84 & 17.36 & 27.69 & 16.2 & 17.4 & 18.0 & 19.1 & 20.5 & 22.5 & 25.3 & 27.7 & 33.2 \\
\hline & $27-28$ & 14,742 & 21.27 & 0.84 & 17.36 & 27.89 & 16.3 & 17.4 & 18.0 & 19.1 & 20.5 & 22.5 & 25.5 & 27.9 & 33.7 \\
\hline & $29-30$ & 14,787 & 21.49 & 0.84 & 17.47 & 28.31 & 16.4 & 17.5 & 18.1 & 19.2 & 20.7 & 22.9 & 25.8 & 28.3 & 33.9 \\
\hline & $31-32$ & 13,283 & 21.77 & 0.84 & 17.58 & 28.76 & 16.4 & 17.6 & 18.2 & 19.4 & 21.0 & 23.2 & 26.3 & 28.8 & 33.7 \\
\hline & $33-34$ & 14,492 & 21.97 & 0.86 & 17.65 & 29.00 & 16.5 & 17.6 & 18.4 & 19.5 & 21.2 & 23.5 & 26.7 & 29.0 & 34.3 \\
\hline & $35-36$ & 14,565 & 22.10 & 0.86 & 17.78 & 29.27 & 16.6 & 17.8 & 18.4 & 19.7 & 21.3 & 23.7 & 26.8 & 29.3 & 34.4 \\
\hline & $37-38$ & 12,807 & 22.21 & 0.86 & 17.91 & 29.00 & 16.7 & 17.9 & 18.6 & 19.8 & 21.5 & 23.8 & 26.8 & 29.0 & 33.6 \\
\hline & $39-40$ & 29,420 & 22.52 & 0.86 & 18.13 & 29.37 & 16.8 & 18.1 & 18.8 & 20.1 & 21.8 & 24.2 & 27.2 & 29.4 & 34.2 \\
\hline & $41-42$ & 30,621 & 22.63 & 0.88 & 18.26 & 29.30 & 17.0 & 18.3 & 18.9 & 20.2 & 22.0 & 24.3 & 27.1 & 29.3 & 33.7 \\
\hline & $43-44$ & 32,708 & 22.78 & 0.88 & 18.43 & 29.17 & 17.1 & 18.4 & 19.1 & 20.4 & 22.2 & 24.5 & 27.2 & 29.2 & 33.3 \\
\hline & $45-46$ & 33,650 & 23.01 & 0.88 & 18.66 & 29.32 & 17.4 & 18.7 & 19.4 & 20.7 & 22.4 & 24.7 & 27.4 & 29.3 & 33.5 \\
\hline & $47-48$ & 34,876 & 23.26 & 0.90 & 18.83 & 29.33 & 17.4 & 18.8 & 19.6 & 21.0 & 22.8 & 25.0 & 27.5 & 29.3 & 33.3 \\
\hline & $49-50$ & 32,689 & 23.35 & 0.90 & 18.97 & 29.21 & 17.5 & 19.0 & 19.7 & 21.1 & 22.9 & 25.1 & 27.5 & 29.2 & 32.9 \\
\hline & $51-52$ & 34,014 & 23.39 & 0.90 & 19.04 & 29.14 & 17.6 & 19.0 & 19.8 & 21.2 & 23.0 & 25.1 & 27.5 & 29.1 & 32.9 \\
\hline & $53-54$ & 41,767 & 23.46 & 0.92 & 19.14 & 29.09 & 17.6 & 19.1 & 19.9 & 21.4 & 23.1 & 25.2 & 27.5 & 29.1 & 32.5 \\
\hline & $55-56$ & 44,976 & 23.59 & 0.92 & 19.22 & 29.17 & 17.7 & 19.2 & 20.0 & 21.5 & 23.2 & 25.3 & 27.6 & 29.2 & 32.5 \\
\hline & $57-58$ & 41,153 & 23.74 & 0.92 & 19.29 & 29.24 & 17.7 & 19.3 & 20.2 & 21.6 & 23.4 & 25.5 & 27.7 & 29.2 & 32.5 \\
\hline & $59-60$ & 41,018 & 23.95 & 0.94 & 19.43 & 29.43 & 17.8 & 19.4 & 20.3 & 21.9 & 23.6 & 25.7 & 27.9 & 29.4 & 32.9 \\
\hline & $61-62$ & 33,313 & 24.14 & 0.94 & 19.56 & 29.64 & 17.8 & 19.6 & 20.5 & 22.1 & 23.8 & 25.9 & 28.1 & 29.6 & 33.3 \\
\hline & $63-64$ & 31,253 & 24.31 & 0.94 & 19.72 & 29.74 & 17.8 & 19.7 & 20.6 & 22.2 & 24.0 & 26.1 & 28.3 & 29.7 & 33.3 \\
\hline & $65-66$ & 28,299 & 24.44 & 0.96 & 19.74 & 29.90 & 17.9 & 19.7 & 20.7 & 22.3 & 24.2 & 26.2 & 28.4 & 29.9 & 33.3 \\
\hline & $67-68$ & 24,972 & 24.47 & 0.96 & 19.81 & 29.94 & 17.9 & 19.8 & 20.8 & 22.4 & 24.2 & 26.3 & 28.4 & 29.9 & 32.9 \\
\hline & $69-70$ & 17,171 & 24.56 & 0.96 & 19.74 & 29.97 & 17.9 & 19.7 & 20.8 & 22.4 & 24.3 & 26.5 & 28.6 & 30.0 & 33.2 \\
\hline & $71-72$ & 17,082 & 24.60 & 0.98 & 19.81 & 30.08 & 17.8 & 19.8 & 20.8 & 22.5 & 24.3 & 26.5 & 28.6 & 30.1 & 33.3 \\
\hline & $73-74$ & 16,771 & 24.59 & 0.98 & 19.70 & 30.02 & 17.7 & 19.7 & 20.8 & 22.5 & 24.4 & 26.5 & 28.6 & 30.0 & 32.9 \\
\hline & 75 & 35,061 & 24.20 & 0.98 & 18.90 & 29.78 & 16.7 & 18.9 & 20.1 & 22.0 & 24.1 & 26.3 & 28.4 & 29.8 & 32.7 \\
\hline
\end{tabular}

Body Mass Index (kg/m², uncertainty: $\mathrm{k}=2$, Confidence Interval [Cl]: 95\%). 
Supplementary Table 2. Korean obesity index standard reference in Kyung-Nam

\begin{tabular}{|c|c|c|c|c|c|c|c|c|c|c|c|c|c|c|c|}
\hline \multirow{2}{*}{ Sex } & \multirow{2}{*}{$\begin{array}{l}\text { Age } \\
(\mathrm{yr})\end{array}$} & \multirow{2}{*}{$\begin{array}{c}\text { Sample } \\
\text { size (No.) }\end{array}$} & \multirow{2}{*}{$\begin{array}{l}\text { Mean } \\
\text { (mean) }\end{array}$} & \multirow{2}{*}{$\begin{array}{c}\text { Uncertainty } \\
\left(\mathrm{kg} / \mathrm{m}^{2}\right)\end{array}$} & \multicolumn{2}{|c|}{$\mathrm{Cl}(95 \%)$} & \multicolumn{9}{|c|}{ Percentile } \\
\hline & & & & & Lower & Upper & 1th & 5th & 10th & 25th & 50th & 75th & 90th & 95th & 99th \\
\hline \multirow[t]{27}{*}{ Female } & $20-24$ & 14,107 & 21.47 & 0.84 & 17.36 & 28.34 & 16.2 & 17.4 & 18.0 & 19.1 & 20.8 & 22.9 & 25.9 & 28.3 & 33.6 \\
\hline & $25-26$ & 10,495 & 21.34 & 0.84 & 17.36 & 27.89 & 16.2 & 17.4 & 18.0 & 19.1 & 20.6 & 22.7 & 25.6 & 27.9 & 33.6 \\
\hline & $27-28$ & 10,212 & 21.42 & 0.84 & 17.47 & 28.23 & 16.4 & 17.5 & 18.1 & 19.2 & 20.7 & 22.8 & 25.8 & 28.2 & 33.6 \\
\hline & $29-30$ & 10,755 & 21.63 & 0.84 & 17.47 & 28.69 & 16.4 & 17.5 & 18.1 & 19.3 & 20.8 & 23.1 & 26.1 & 28.7 & 34.4 \\
\hline & $31-32$ & 9,938 & 21.93 & 0.86 & 17.63 & 28.98 & 16.4 & 17.6 & 18.3 & 19.5 & 21.2 & 23.4 & 26.6 & 29.0 & 34.8 \\
\hline & $33-34$ & 11,827 & 22.07 & 0.86 & 17.72 & 29.03 & 16.5 & 17.7 & 18.4 & 19.7 & 21.4 & 23.7 & 26.6 & 29.0 & 34.1 \\
\hline & $35-36$ & 12,359 & 22.20 & 0.86 & 17.87 & 29.05 & 16.7 & 17.9 & 18.6 & 19.8 & 21.5 & 23.7 & 26.9 & 29.1 & 34.2 \\
\hline & $37-38$ & 11,684 & 22.38 & 0.86 & 18.03 & 29.04 & 16.8 & 18.0 & 18.7 & 19.9 & 21.7 & 24.0 & 27.0 & 29.0 & 34.2 \\
\hline & $39-40$ & 29,844 & 22.71 & 0.88 & 18.20 & 29.62 & 16.9 & 18.2 & 18.9 & 20.2 & 22.0 & 24.5 & 27.4 & 29.6 & 34.2 \\
\hline & $41-42$ & 31,566 & 22.81 & 0.88 & 18.37 & 29.41 & 17.1 & 18.4 & 19.1 & 20.4 & 22.2 & 24.5 & 27.3 & 29.4 & 33.9 \\
\hline & $43-44$ & 32,105 & 22.98 & 0.88 & 18.59 & 29.38 & 17.3 & 18.6 & 19.3 & 20.7 & 22.4 & 24.7 & 27.4 & 29.4 & 33.5 \\
\hline & $45-46$ & 33,629 & 23.20 & 0.90 & 18.82 & 29.33 & 17.4 & 18.8 & 19.6 & 21.0 & 22.7 & 24.9 & 27.5 & 29.3 & 33.3 \\
\hline & $47-48$ & 33,204 & 23.37 & 0.90 & 19.03 & 29.34 & 17.7 & 19.0 & 19.7 & 21.1 & 22.9 & 25.1 & 27.6 & 29.3 & 33.3 \\
\hline & $49-50$ & 30,215 & 23.50 & 0.90 & 19.15 & 29.34 & 17.7 & 19.1 & 19.9 & 21.3 & 23.1 & 25.2 & 27.6 & 29.3 & 32.9 \\
\hline & $51-52$ & 29,369 & 23.55 & 0.90 & 19.15 & 29.32 & 17.7 & 19.1 & 20.0 & 21.4 & 23.1 & 25.2 & 27.6 & 29.3 & 33.2 \\
\hline & $53-54$ & 35,495 & 23.63 & 0.92 & 19.29 & 29.21 & 17.7 & 19.3 & 20.1 & 21.5 & 23.2 & 25.3 & 27.6 & 29.2 & 32.8 \\
\hline & $55-56$ & 36,181 & 23.78 & 0.92 & 19.38 & 29.38 & 17.9 & 19.4 & 20.2 & 21.6 & 23.4 & 25.5 & 27.8 & 29.4 & 32.9 \\
\hline & $57-58$ & 31,874 & 23.91 & 0.92 & 19.40 & 29.43 & 17.8 & 19.4 & 20.3 & 21.8 & 23.6 & 25.7 & 27.9 & 29.4 & 32.9 \\
\hline & $59-60$ & 30,970 & 24.13 & 0.94 & 19.56 & 29.64 & 17.9 & 19.6 & 20.5 & 22.1 & 23.8 & 25.9 & 28.1 & 29.6 & 32.9 \\
\hline & $61-62$ & 25,151 & 24.29 & 0.94 & 19.63 & 29.74 & 17.9 & 19.6 & 20.5 & 22.2 & 24.0 & 26.1 & 28.3 & 29.7 & 33.3 \\
\hline & $63-64$ & 23,568 & 24.37 & 0.96 & 19.74 & 29.86 & 17.9 & 19.7 & 20.7 & 22.3 & 24.1 & 26.2 & 28.3 & 29.9 & 33.3 \\
\hline & $65-66$ & 20,671 & 24.48 & 0.96 & 19.72 & 29.97 & 17.9 & 19.7 & 20.7 & 22.4 & 24.2 & 26.3 & 28.4 & 30.0 & 33.3 \\
\hline & $67-68$ & 18,692 & 24.44 & 0.96 & 19.71 & 29.90 & 17.7 & 19.7 & 20.7 & 22.4 & 24.2 & 26.3 & 28.4 & 29.9 & 32.9 \\
\hline & $69-70$ & 12,840 & 24.44 & 0.96 & 19.48 & 29.90 & 17.5 & 19.5 & 20.5 & 22.3 & 24.3 & 26.4 & 28.5 & 29.9 & 33.2 \\
\hline & $71-72$ & 13,643 & 24.32 & 0.98 & 19.40 & 29.90 & 17.5 & 19.4 & 20.4 & 22.2 & 24.1 & 26.2 & 28.4 & 29.9 & 33.2 \\
\hline & $73-74$ & 13,781 & 24.24 & 0.98 & 19.22 & 29.73 & 17.3 & 19.2 & 20.3 & 22.1 & 24.1 & 26.2 & 28.4 & 29.7 & 32.8 \\
\hline & 75 & 32,785 & 23.54 & 1.00 & 18.22 & 29.33 & 16.2 & 18.2 & 19.3 & 21.2 & 23.4 & 25.7 & 27.9 & 29.3 & 32.4 \\
\hline
\end{tabular}

Body Mass Index ( $\mathrm{kg} / \mathrm{m}^{2}$, uncertainty: $\mathrm{k}=2$, Confidence Interval [Cl]: 95\%). 